\title{
RESEARCH
}

\section{A Plead to Nepali Diaspora: An Urge for Homecoming}

Harihar Poudel

ABSTRACT

KEY WORDS

Diaspora

Economic Prosperity

Patriotism
Nepal is in dire need of help from the Nepalese Diasporas around the world for her progress and prosperity to come off her backwardness and poverty. Research reflects that education is the major remedy in solving the burning problems of poverty and backwardness. Ironically, educated youngsters have forgotten this land by expensing their skills in other countries of the world readily accepting the degree of second-grade citizenship. This piece aims at making a critical surgery on the hollowness of Nepali Diasporas and make an appeal for them to return back to their home country with well-disposed intention of building their own country and creating their own identity by bringing reference of some literary and non-literary texts.

IT IS A SHOCKING FACT to all that the word and concept of 'Diaspora,' which until a few years ago was unknown even to many academics and about which the general public were unaware, has gained ground in the laymen's psyche. 'Diaspora' (Dufoix, 2008), etymologically originated from Greece, refers to the dispersal throughout the world of people with the same territorial origin. Nonetheless it can be associated with the terms dispersion, displacement and dissemination. In fact, people of a particular nationality, dispersed and disseminated throughout the world as emigrants, is called Diaspora. Oxford dictionary however has a narrow vision for the term Diaspora that it is the settling of the Jewish people among various non-Jewish communities after they were exiled in $538 \mathrm{BC}$. But the term Diaspora these days represents every undercurrent of dispersed nationality and cross border emigrants from different sovereign countries of the world no matter whatever may be the purpose of their dispersion. In the past few years, the term Diaspora has become a loose reference confusing categories such as immigrants, guest-workers, ethnic and "racial" minorities, refugees, expatriates and travelers. So much so that, if a Nepali resides in the Bihar province of India or the Tibetan boarder of china, than unquestionably, the person forms the Nepali Diaspora.

Nepali expatriates living in the different corners of world have been creating some strong cult of Nepali Diaspora. According to Adhikari, "the early Non- 
Resident Nepalis (NRN's), after Nepal became a nation-state almost 300 years ago, were moving to the immediate vicinities in neighboring countries in search of livelihoods. Subsequent to the Sugauli Treaty in 1816 with East India company, the famous "Lahure" culture of Nepalese serving in foreign army became the mainstay of employment for many people and provided an opportunity for Nepalese to see the world and demonstrate their bravery"(Adhikari,2010). Nepal's increasing contact with the West was triggered since her liberation from Rana rule in 1951. The rate of return of diasporas is so minimal in comparison to the outflow predicts that Nepali Diaspora will make no significant contribution in building up of their country. The testimony for this can be traced upon with the craze for Diversified Visa lottery sponsored by USA and a permanent settlement benefit given to former army men's family provided by the UK. After they were approved for permanent settlements, most of them were found selling their property, transferring their balances and leaving nothing related to this country.

Vertovec (1999) has described the Diaspora effort to settle in the new land as a continuous process, but also one where they begin to define their identity (p.6). In this direction, Nepalese not only began to evolve new cultural traits which were a mix of both worlds, but also began a process of reinventing their identity around cultural markers, which in most cases were traditionally Nepali like festivals, customs, rituals and language. The common history becomes a bond they share and draw from, for reassurance in their new homeland. This is strong evidence to the longing for Nepaliness in tradition and culture. If they would like to share the aura of Nepali culture, cuisines and costumes, why should they make second thoughts in returning to their country? The country is hankering for the return of her sons and daughters with a motive of giving priorities over her development.

\section{NRNs and Diaspora}

Some of the critics, leaders and Medias however associate the return of the NRNs and forming the society of NRN by long term settlers in a foreign geography with philanthropy and patriotism. Similarly Pramod Dhakal is also supportive to the idea as he states, "Despite good intentions, it is not practical for most members of the Diaspora living in advanced countries to return to their native country. That is due to a number of personal and professional reasons, including educational opportunities for children, health and medical reasons, building a pensionable retirement, opinions of family members, and fear of instability and uncertainty in one's native land, particularly in the case of poor countries" (Dhakal, 2010). But, since their return, NRNs investments made here in Nepal are focused on some profit motive organizations like media houses, private hospitals, hotels and resorts. It would not be out of place to say that, they are using Nepal as a safer place for launching their new products and industries with full support from the government in terms of the rate of taxation, excise and other duties. It is a matter of shame that they claim to deserve the right of dual citizenship for absolutely business purpose. If they are true patriots why cannot they give up their citizenship of a foreign land and come to serve this country in a true spirit of patriotism?

Diaspora can never be a homogenous group, but its promoters like to portray it as such in order to emphasize its importance. However, the unity of the Diaspora must not be taken for granted. Why would dispersion, exile and co-presence be enough 
to instill a sense of belonging in an often distant and misunderstood social form (i.e. the diaspora), in individuals who have not necessarily followed the same social and professional trajectories? As we shall see, far from uniting the community, the way in which the Nepalese Diaspora uses and makes postings on the Web give the impression that the term "Diaspora" has been confiscated for the benefit of an active minority. This is how Tristan Brusle has criticized the websites related with the Nepalese Diaspora that it "is a project, a position launched by the elite above who deliver an official discourse that the people below are supposed to follow. Diasporic websites are a tool for implementing this policy of forming the group (Brusle, 2012). It is worth mentioning that so called unity in the websites in terms of their postings do not make the entire Diasporas united as there is the domination of the few over the many. They seem binding together with a sense of Nepaliness, otherwise their remains no fraternity, cooperation and unity. As Brusle states that, "the use of English as the main language on the Nepalese diasporic web (61\% of all websites use English as their main language) highlights the practices of relegating a large part of Nepalese expatriates (Brusle, 2012).

\section{Scenario of Nepalese Diaspora}

It is the geostrategic location and the unvisionary leadership that has left Nepal to be a poor state in terms of economy. But, there are quite a lot of things that always hold the head of Nepalese high. A small landlocked country in the south- east Asia sand-witched between two emerging giantsChina towards the north, and India being adjacent tri-directionally, Nepali Diaspora is nonetheless in equilibrium vis-a- vis the two states. And, the nation has maintained her sovereign integrity till the date. However, during the colonial period also
Nepali Diasporas weeded in India and Hongkong in the form of cheap manual laborers. Lopita Nath is trying to depict in his own words that, "the Nepali immigration to countries like India and Hong Kong and elsewhere in South and Southeast Asia dates back to the colonial period when the British began to recruit the Nepalis for the British army (Gurkha battalions) and also as laborers to work on the tea gardens and coal mines and later for any sundry job on a modest payment. This began a tradition of migration" (Nath, 2009, p.108). Nath must be trying to pinpoint the idea that the tendency of becoming "lahure" is not a boon but an alternative to serve in a foreign land by seeking some escapist route to earn easy money.

Asia as a continent itself was discovered later as Columbus mistakenly landed on the then territory of present USA. It is with the discovery of Asia that the Nepali Diaspora came to be noticed and studied. This is what Evelyn Hu-Dehart and Kathleen Lopez have jointly stated in their article Asian Diasporas in Latin America and the Caribbean: A Historical Overview about Columbus' journey that, "Curiously, although Columbus was looking for a new route to Las Indias, Asia was quickly forgotten in the construction of New World history, perhaps because it soon became obvious that Columbus missed his mark and reached lands previously unknown to his compatriots in Europe. But Columbus persisted in his illusion that he had indeed reached Asia, and gave the native peoples he encountered the enduring misnomer of "Indians"- a constant reminder, it would seem, that the idea of Asia in the invention of America was fixed at America's inception" (HuDehart and Lopez,2008, p.9). By this citation we can trace the strong evidence that Asia and the Asian countries would have been more powerful and well developed if and otherwise discovered 
intimely by the Europeans. Asia, also recognized as the continent of extreme, is a land of bounties, and Europeans and the western world were keeping some ill- intentions to conquer this land. This is why they had navigated towards the east. But, educated Nepalese have made this place a disposable item that is once used and thrown away. What is the worth of their education when then sway in the hands of the foreigners as clay to a potter?

There is no doubt among observers and analysts that only an increasing flow of foreign aid, remittance and loans have kept Nepal from falling on to the gorge of insolvency. Yet, there seemed to be little evidence suggesting that the aid had, despite good intentions, alleviated mass poverty and uplifted the society as a whole. It is an unchallengeable and unavoidable destiny of Nepalese that they have to leave their country for earning their daily bread. No matter their services to a foreign country have given them privileges for the upliftment of their status, it has also increased dependency and has ruined the family, the society and the country as a whole. Widespread Nepalese citizenry, some of them have been completely forgotten by their national kinsfolk, are still struggling to keep their identity in the first world countries. Although they are regarded as the secondary citizens having hyphenated identity and lost in the labyrinth of cultural pluralism, they are attempting to create Nepali Diaspora. East Indians, or South Asians, consist of many religious and ethnic groups. They have indeed created religious groupism and integration which may lead to favoritism and communal violence. As Vetrovec puts it, "Ismailis and other Muslims, Jains, Sikhs, Parsis, with Hindus being the largest by far, leading some scholars to focus specifically on the Hindu diaspora" (Vertovec, 2000).

\section{Diaspora in the West and East}

In the past, however, Diasporic existence was the cause of political upheavals and unpleasant situations. But these days' people tend to accept this identity- with a sense of pride and honour. People getting foreign citizenship rights, green cards and other forms of permanent settlements exhibit some sense of superiority in their attitude. For a number of high-impact historical stressors, such as the Holocaust, World War II, the Korean and Vietnam Wars, and other upheavals of the 1960s and 1970s around the world, people fled to some safer countries and the literature produced by such writers reflected the trauma and trepidation and a pathetic call to visit their place of origin. People fleeing for survival are always haunted by the memory of their homeland and are absolutely submerged in the sea of nostalgia. Mahesh Paudyal however disagrees with the idea that all emigrants cannot be categorized as particular Diaspora unless they have left some long lasting impact upon their country. As he mentions that, "the real Diasporas are the Nepalis in Bhutan, Manipur and Assam in India, Burma, Hong Kong and the UK. Smouldered by the heat of history, crushed by the cruelty of autocratic or ethnic powers, displaced by natural calamities, pressed hard by poverty to migrate for good, most of these people entered Bhutan, northeast India and Burma and lost every possibility of return. Their progeny form the real Diasporic Nepali population. In Hong Kong and the UK, the children of the former army men and their relatives make up the population. Singapore, if it holds any Nepali population with military roots, too might be counted. Elsewhere, Nepali Diasporas do not exist. The literature of the Nepali Diaspora, therefore, should mean literature by these people from such hitherto unexplored regions." There appears no reason to doubt that the 
survivors cope with these memories effectively, just as they did with the original experiences. Again, the process is sometimes described in questionably pathogenic terms: "Fifty years after the Holocaust, the memory of those traumatic years continues to haunt the lives of the survivors. Even though one marvels at the remarkable adaptation of child survivors of the Holocaust, the anguish of the past remains a part of their conscious and unconscious life" (Kestenberg \& Fogelman, 1994, p. 204).

Short term stay in other country for economic reason or for education is considerable. But if one makes waste of his/her life and skills in a so called prosperous country blinded by the sense of superiority is an idiosyncrasy. We must not forget to learn a lesson from Indian Diasporas who have contributed in the nation building from implementing the skills achieved in a foreign land. In general, many problems can be solved through scholarly collaboration, or only by Diaspora enthusiasts, if such problems are defined clearly. When applying this technique, much knowledge and understanding can be developed on the natural and artificial resources of the country. Knowing about what one has is a necessary step in discovering what can be done in the future. When possibilities are revealed, scholars from around the world would be interested in scholarly and other technological collaborations. In this regard Dr. Pramod Dhakal highlights on the need for favorable conditions for Diasporas return to their homeland "a daring young person at the beginning phase of a career is more likely to return for entrepreneurial pursuits than an established professional. Therefore, it is better for a country to develop institutions that can utilize what the Diaspora know from where they live and work without any need to return to their native places.
Since all researchers around the world are seeking new opportunities for creative endeavors, being able to inspire collaboration in problem solving and research should outweigh the issue of physical return." (Dhakal, 2010)

I would also like to point out the role of the government in facilitating the Diasporas with congenial atmosphere and considerable pay and perk so that they need not get frustrated in their own land .Diasporas' potential role as agents of development cannot and should not be easily dismissed. Factors such as the diaspora's size, skill levels, culture and home bias and the socioeconomic and political conditions at both origin and destination are just some of the factors to consider when determining appropriate policy interventions. Strategic thinking is a key. If the past is a good indicator of the future, then the prospect for many countries of origin is quite good. For example, in the 1990s the Chinese and Indian Diasporas did not wait for all of India and China to develop, but found windows of opportunity in Bangalore and Shanghai. Creating just one point of attraction for Diasporas can establish a foundation for Diasporas engagement even when other building blocks are few. The government also should develop some strong policy to motivate the Diasporas worldwide in returning back to their homeland with a sense of pride and honour. According to Adhikari, "the Nepali Diaspora has to think big and make big plans. A massive investment in infrastructure, education and technology is what Nepal needs to take off. The Diaspora is capable of providing a big push to the government and private sector in Nepal to build a formidable partnership. Nepali government, its private sector and the Diaspora can create a winning collaboration to create and implement large-scale development programs in 
Nepal" (Adhikari, 2010). Policymakers in Nepal must recognize the value that Diaspora populations bring to development efforts at home, not just as senders of remittances but also as sources of human capital and direct and indirect (capital market) investments. Government can facilitate such contributions in several ways, from creating conducive legal frameworks and diaspora-centred institutions to initiating programmes specifically targeting Diasporas as development actors.

\section{Travel for self- Development}

The great philosophers, since time immemorial, have left their homeland in the quest of knowledge, innovations and findings. Confucius left $\mathrm{Lu}$ (a place in present day Shandong, China) and travelled around many countries in China before returning to his homeland. Buddha left his birthplace long before returning to Kapilvastu as a monk. Marco Polo traveled in Central Asia and China for 24 years before returning to Venice. Marco Polo's influence in Italy has been greater than in China. Buddhism flourished in Buddha's native land before it spread throughout the world. Christopher Columbus made a greater impression in Spanish and other Europeans countries than to the natives of the Americas. People like Maharana Pratap and Ashoka travelled to different locations to explore knowledge and spread their influence. In Nepal also people like Araniko and Bhrikuti travelled to China as early forms of Diaspora and disseminated the art and culture of their country. However, all of them are not recognized by the name of the country they travelled but, by the name of the country they were born. National identity plays a significant role in naming and faming. That was long before the birth of telecommunication. Today, satellite communication systems allow a person or institution to reach an entire population of a country in a single broadcast. Thus the power to influence people has increased exponentially. Today, the Diaspora expertise in education, research, collaboration, decision making support, information and technology can be disseminated at an unprecedented speed and scale.

\section{Superiority of Nationality}

Diaspora awareness seems more political approach than a bond of nationality across the country. Diaspara movement around the globe is run by a few while most of them are still unaware of it or simply are indifferent to it. Some privileged and aware people are taking chances to manipulate the Diaspora community in the name of NRN election, Political influence and other kind of international movements. The Nepalese Diaspora is a project, a position launched by the elite above who deliver an official discourse that the people below are supposed to follow. Diasporic websites are a tool for implementing this policy of forming the group. They represent a practice and a means to express allegiance to the country of origin or to the created social form. They contribute to the creation of a nascent Diaspora through the links they have forged with each other and through performativity that is by the mere fact that they exist and call themselves a Diaspora. They correspond to a policy of making scattered groups visible and of gathering them under terms (Diaspora, NRN), aimed at the group's self-awareness. Internet is a catalyst, proof of the existence of a social group whose objectives to preserve the Nepali culture, to ensure mutual help or to contribute to Nepal's development, are said to be shared by all. In this way, Creation of Diaspora seems a mega project to detach a national by the entanglement in the foreign affairs, while the Diaspora community remains with memories and nostalgia to join 
their own home land. Although much hype has been created on Disapora and National solidarity throughout the world, whatever achievements and results are out shows no sign of benefit to their country of origin. In this regard we can trace the example of Prashant Tamang, Darshan Rauniyar, Udit Narayan and many others who are able to catch the Nepalese sentiments in their personal interest till the date.

Most of them therefore, must one day, return to their homeland with a sense of patriotism and serve this country that is in peril. Rather than saving a country which is not yours own, it is better to breathe last on your own soil. This is how the great poet L.P Devkota discards serving on foreign land with strong dislike for wealth earned from it: "Hataka maila sunaka thaila ke garnu dhanale, Saga ra sisnu khayeko besa aanandi manale. It is better to eat the nettles and leaves on our own country with a pleased heart rather than amassing cash and kinds that are simply the dust at our hands " (Devkota,2065,p.2). Similarly, aversion to foreign country's service can only help in uplifting the country lurch in the labyrinth of despairity. Our country is pleading her true patriots to make an uttermost endeavor in saving her from the dark clouds of poverty and economic backwardness. Nationalists cannot return the genie of social identity to the bottle of the territorial nationstate confining them within the national territory. Globalization has put paid to that possibility and in so doing enhanced the practical, economic and affective roles of Diasporas, showing them to be

\section{REFERENCES}

Adhikari, A. P. (2010, 07 10). Diasporas in Nepal's Development. Republica . Kathmandu, Nepal: Republic Media. particularly adaptive forms of social organization. In this regard, it is worth mentioning the voice that reflects the bemoaning and bewailing of a foreigner by Fawaz Turki: "I have an ache to be home, except that I don't know where home is. May be somewhere between dream and nothingness, somewhere in the geography of my soul” (Turki, 1988, p. 77)

Rather than sharing a troubled relationship with host societies suggesting a lack of acceptance at the least or the possibility that another calamity might befall the group, they will soon be aware of the situation and make a U-turn to their birthplace. Our intention here is not to say our brethren a big "NO" in this country, but our attempt is to make them return to this land which is wallowing in the pond of poverty. We are hopeful that the true citizenry of this nation will soon realize the call of the country by awakening from the deep dream of economic prosperity from a service to a foreign land. Come and serve your country after you have gained some skills and novel ideas along with the sufficient amounts that help your country grow at a faster pace. After all we all have Nepali hearts, the grace of Lord Buddha, the revolutionary spirit of the brave Gurkha and the blood in our veins is an admixture of the water flown from the roof of the world -Everest and similar other snow-clad mountains. Why should we slacken our dignity at the hand of the foreigners as done by a slave to his master while there are immense possibilities and a hopeful future?

Bruslé,T.(2012,4). Nepalese diasporic websites, signs and conditions of a diaspora in the making?, e-Diasporas Atlas.

Devkota, L. P. (2065). Munamadan (25 ed.). 
Kathmandu: Sajha Publishers.

Dhakal, P. (2010, 11 25). Diaspora: How They Matter in Education and Knowledge Translation. CFFN.

Dufoix S. (2008) Diasporas. Berkeley: University of California Press. (First published in French, 2003.)

Hornby, A. S. (2010). Oxford Advanced Learner's Dictionary. 8. Oxford University Press.

Kestenberg, J. S., \& Fogelman, E. (Eds.) (1994). Children during the Nazi reign: Psychological perspective on the interview process. Westport, CT: Praeger.

Hu-Dehart,E., \& Lopez,K . (2008). Asian

Harihar Poudel is an Assistant Professor in English and Communitcation at Nepal Tourism and Management College, Pokhara. He has more than
Diasporas in Latin America and the Carribean:A Historical Overview. AfroHispanic Review , 27 (Spring), 9.

Nath, L. (2009). A little of Nepal: Nepali diaspora in the US in an age of globalizatioin. Bodhi , 1 .

Paudyal, M. (2013, 10). The Nepali Diaspora.

Retrieved 9 21, 2013, from http://www.ekantipur. com

Turki, F. (1988). Monthly Review. Soul in Exile: Lives of a Palestinian Revolutionary.

Vertovec, S. (2000). The Hindu Diaspora: Comparative Patterns. New York: Roudedge.

7 years experience in teaching. His area of interest in research includes Nepali and International literature. email : peacepoudel@gmail.com 